\title{
Evaluation of Amlodipine Inhibition and Antimicrobial Effects
}

\author{
Ziyue Yi ${ }^{1,}$, Zhu Pei ${ }^{2}$, Ma Xiaoyan ${ }^{3}$ \\ ${ }^{1}$ Case Western Reserve University, Cleveland, United States \\ ${ }^{2}$ Hengyang Normal University, Hengyang, China \\ ${ }^{3}$ Nanjing University of Chinese Medicine, Nanjing, China
}

Email address:

yiziyuework@gmail.com (Ziyue Yi),787060387@qq.com(Zhu Pei),simple8081@126.com (Ma Xiaoyan)

${ }^{*}$ Corresponding author

\section{To cite this article:}

Ziyue Yi, Zhu Pei, Ma Xiaoyan. Evaluation of Amlodipine Inhibition and Antimicrobial Effects. International Journal of Pharmacy and Chemistry. Vol. 5, No. 1, 2019, pp. 12-14. doi: 10.11648/j.ijpc.20190501.12

Received: February 19, 2019; Accepted: March 25, 2019; Published: April 15, 2019

\begin{abstract}
Antibiotic resistant pathogens is the an urgent challenge of the medicine field. To counter these pathogens, the antibiotic assisting drugs is an ideal choice. Assisting drugs can improve the efficiency of the treatment without further induce of antibiotic resistance. Amlodipine (AML) is one of the most common generic cardiovascular drug for lowering blood pressure. In previous studies, amlodipine was suggested to have some antibiotic properties. The MIC is not very low for amlodipine against these pathogens. However, the findings imply amlodipine potential to be repurposed as assisting drug and its inhibition of $\beta$-lactamase. To further discover and verify its potential of antimicrobial drug, amlodipine was tested for $\beta$-lactamase inhibition, and its synergistic effects were investigated against methicillin-resistant Staphylococcus aureus (MRSA). The compound was found to inhibit $\beta$-lactamase mixture ( 3 distinct species) in broad spectrum. Cephalosporins requires high concentration ( $>=64$ $\mathrm{ug} / \mathrm{ml})$ to inhibit MRSA; combine both amlodipine and cephalosporins, the MIC only requires $8 \mathrm{ug} / \mathrm{ml}(4 \mathrm{ug} / \mathrm{ml} \mathrm{amlodipine}+4$ $\mathrm{ug} / \mathrm{ml}$ Cefuroxime) in total, with FIC lower than 0.1 for strong synergistic effect. Both enzyme assay and bacterial tests indicate amlodipine as an ideal assisting drug for antibiotics; one of the mechanism is $\beta$-lactamase inhibition.
\end{abstract}

Keywords: Amlodipine, $\beta$-lactamase, MRSA, Synergic

\section{Introduction}

Amlodipine (AML) is a classical drug used for high blood pressure. Although many therapeutic combinations including amlodipine exist, such combinations have all been designed for cardiovascular purpose. Examples include amlodipine/ atorvastatin and amlodipine/ aliskiren. [1]

In previous studies, amlodipine alone was found to inhibit some pathogens, including a wide range of bacteria, fungi and even parasites. [2-4] In a recent study and clinical trial, amlodipine was discovered to also reverse the antibiotic resistance of A. baumannii. [5-6] However, no study of the relationship between amlodipine and gram positive resistant bacteria has been conducted.

MRSA is a multi-antibiotic resistant pathogen. Although usually mild, MRSA can accidentally infect humans as a pathogen. Due to its antibiotic resistance, MRSA can be quite lethal once the host is infected, although the mortality rate varies (13\% to $21.8 \%)$ among studies. [7-8] The common symptoms of MRSA infection include fever and skin damage. [7] Though the well-known carrier of PBP2A, MRSA also contains $\beta$-lactamase to counter antibiotics. [9-11] In this study, MRSA was chosen to be a representative gram-positive bacteria model.

$\beta$-lactamases are responsible for the antibiotic resistance. Four classes of $\beta$-lactamases are identified. Among them, Class A, C, D are similar, use serine as the catalytic residue; Class B uses Zinc as the catalytic unit, render some inhibitors useless.

In this experiment, amlodipine was tested for $\beta$-lactamase inhibition. Then, amlodipine was combined with other agents and tested against MRSA. We discovered that amlodipine can inhibit distinct $\beta$-lactamases and exhibited synergistic antimicrobial effects in combination with cephalosporins. 


\section{Method}

\subsection{Materials}

Hefei Bomei Biotech Co. provides:

Nitrocefin powder $95 \%$ purity

$\beta$-lactamase mixture $1000 \mathrm{U} / \mathrm{mg}$

CAS 9073-60-3

Shanghai Shuye Co. provides:

Amlodipine beysalt 99\%

Jiangsu Province Cooperation of Chinese and Western Medicine Hospital provides:

MRSA strain: 01040206763231

Antibiotics

\subsection{B-lactamase Enzyme Activity Assay}

As shown above, the enzyme powder contains three distinct species of $\beta$-lactamases, includes $A, B, D$. The experiment wants to cover both type B and the other types. Type B enzymes use $\mathrm{Zn}$ as the catalytic residue rather Ser amino acid, which brings quite different properties.

$\beta$-lactamase and nitrocefin was prepared in PBS solution; amlodipine was added in DMSO solution.

Optical Density at $510 \mathrm{~nm}\left(\mathrm{OD}_{510}\right)$ was used for enzyme activity determination. Nitrocefin solution is originally yellow, but once digested by $\beta$-lactamase, the solution becomes red. [12] The peak absorption has been determined to be $510 \mathrm{~nm}$. If inhibition occurs, low absorption at $510 \mathrm{~nm}$ should be observed, and the color should remain yellow.

After color was stabilized, $\mathrm{OD}_{510}$ value was recorded.

\subsection{Bacterial Test}

Both bacteria and drugs were prescribed or under biosafety control. The experiment was performed in the biosafety lab provided by Jiangsu Province Cooperation of Chinese and Western Medicine Hospital.

MRSA were stimulated before the test. The bacteria were incubated with Mueller Hinton broth at $37 \mathrm{C}$ for $48 \mathrm{hr}$. $\mathrm{OD}_{600}$ was adjusted to 0.5 before load to the 96 -well plate. For each well, 100uL of bacterial liquid was added. Once the bacteria added, the OD value of each well was used as the blank.

The antibiotic treatments were applied in each well. The concentrations of the treatments were halved after every trial. Amlodipine was combined with antibiotics at a 1:1 ratio, where $32 \mathrm{ug} / \mathrm{mL}$ of the treatment consisted of $16 \mathrm{ug} / \mathrm{mL}$ of amlodipine and $16 \mathrm{ug} / \mathrm{mL}$ of antibiotics. For each well, 100uL of treatment (DMSO solution) was added.

Once the treatment was added, the plate was incubated for more than 20 hours. The $\mathrm{OD}_{600}$ was recorded as the relative bacterial concentration.

The minimum inhibitory concentration (MIC) was calculated and reported. For the combined amlodipine treatments, the fractional inhibitory concentration (FIC) was used. [5]

$\mathrm{MIC}_{\mathrm{A}+\mathrm{B}}$ indicates the MIC for the antibiotics combined with amlodipine. $\mathrm{MIC}_{\mathrm{A}}$ or $\mathrm{MIC}_{\mathrm{B}}$ indicates the antibiotics or amlodipine alone, respectively.

$$
F I C=\frac{M I C_{A+B}}{M I C_{A}}+\frac{M I C_{A+B}}{M I C_{B}}
$$

FIC $<0.5$ indicates that amlodipine and the antibiotics are strongly synergistic

FIC $0.5-1$ indicates that amlodipine and the antibiotics are synergistic

FIC 1-2 indicates that amlodipine is irrelevant to the antibiotics

FIC $>2$ indicates that amlodipine inhibits the effects of the antibiotic

Table 1. The results of the enzyme activity assay.

\begin{tabular}{lll}
\hline Group & Content (PBS PH=7) & $\begin{array}{l}\text { Average } \\
\text { OD }_{\mathbf{5 1 0}}\end{array}$ \\
\hline 1 & Nitrocefin $(0.5 \mathrm{mg} / \mathrm{ml})$ & blank \\
2 & Nitrocefin $(0.5 \mathrm{mg} / \mathrm{ml})+0.5 \mathrm{mg} / \mathrm{ml} \mathrm{AML}$ & -0.157 \\
3 & Nitrocefin $(0.5 \mathrm{mg} / \mathrm{ml})+1 \mathrm{mg} / \mathrm{ml} \mathrm{AML}$ & -0.2695 \\
4 & Nitrocefin $(0.5 \mathrm{mg} / \mathrm{ml})+25 \mathrm{u} \beta$-lactamase & 0.624 \\
5 & Nitrocefin $(0.5 \mathrm{mg} / \mathrm{ml})+25 \mathrm{u} \mathrm{PC1}+0.5 \mathrm{mg} / \mathrm{ml} \mathrm{AML}$ & -0.155 \\
6 & Nitrocefin $(0.5 \mathrm{mg} / \mathrm{ml})+25 \mathrm{u} \mathrm{PC} 1+1 \mathrm{mg} / \mathrm{ml} \mathrm{AML}$ & -0.275 \\
\hline
\end{tabular}

\section{Results and Discussion}

\subsection{P-lactamase Enzyme Activity Assay}

Amlodipine was added to DMSO solution, some precipitation was observed. After centrifugation and removal of the precipitates, the entire system became lighter than the blank.

For the positive control (group 4), the solution became red, and the OD readings increased. Groups 5-6 showed the same results as the negative controls (groups 2-3). Do remember the $\beta$-lactamase mixture contains three different species of the enzymes. Compare to the facts of clavulanic acid or sulbactam, clavulanic acid and sulbactam are usually resisted by type $B$ $\beta$-lactamases. The inhibition of all the $\beta$-lactamases suggested amlodipine has a much wider range of inhibition. The results are shown above in Table 1.

The $\mathrm{OD}_{510}$ readings were recorded when the color did not change any further. Based on the results, the test group did not change color as observed for the positive control; instead, the test groups were identical to the negative control. This indicates inhibition of all of the $\beta$-lactamases.

\subsection{Bacterial Test}

As shown in Table 2, the calculated MIC and FIC are given. The ratio for the amoxicillin: clavulanic acid is $3: 1$, which was pre-mixed as the default factory setting. From the literature, the MIC of sulbactam is $24 \mathrm{ug} / \mathrm{ml}$ at a 2:1 ratio. [13]

In the experiment, amlodipine demonstrates significant better synergistic effect than clavulanic acid and sulbactam. According to the results, amlodipine can be combined with cephalosporins to achieve a better effect. Ideally, $4 \mathrm{ug} / \mathrm{ml}$ (8ug/ml overall treatment) of amlodipine is sufficient to augment cephalosporins. Among cephalosporins, cefuroxime shows significantly better bacterial inhibition than the others. The final FIC of cefuroxime was 0.125 , indicating a very strong synergistic effect. 
Table 2. The results of the bacteria test

\begin{tabular}{|c|c|c|c|c|c|c|}
\hline \multirow{2}{*}{ Treatments } & \multicolumn{3}{|c|}{ MIC (ug/mL) } & \multicolumn{3}{|l|}{ FIC } \\
\hline & $10 \mathrm{hr}$ & $20 \mathrm{hr}$ & $22 \mathrm{hr}$ & $10 \mathrm{hr}$ & $20 \mathrm{hr}$ & $22 \mathrm{hr}$ \\
\hline Amlodipine & 128 & 128 & 128 & & & \\
\hline Cefazolin & 128 & 64 & 64 & & & \\
\hline Cefuroxime & 256 & 128 & 128 & & & \\
\hline Ceftriaxone & 16 & 16 & 16 & & & \\
\hline Amoxicillin + Clavulanic acid & 32 & 32 & 32 & & & \\
\hline Amlodipine + Cefazolin & 64 & $16(18 \mathrm{hr})$ & $16(20 \mathrm{hr})$ & 1 & 0.375 & 0.375 \\
\hline Amlodipine + Cefuroxime & 8 & 8 & 8 & 0.094 & 0.125 & 0.125 \\
\hline Amlodipine + Ceftriaxone & 8 & 8 & 8 & 0.5625 & 0.5625 & 0.5625 \\
\hline
\end{tabular}

\section{Conclusion}

In conclusion, amlodipine demonstrated inhibition of a wide range of $\beta$-lactamases. The inhibition is not affected by the distinct feature of type B $\beta$-lactamase. The combination of amlodipine and cephalosporins can inhibit MRSA growth synergistically, and the inhibitory effect is more powerful than that of clavulanic acid. Combine both enzymatic and bacterial tests, the synergistic effect is implied to be contributed by the inhibition of $\beta$-lactamases. To conclude, amlodipine has the potential of antimicrobial drugs.

\section{Acknowledgements}

The content in this paper already in pending of patent application.

CN201810124799.3

Applied: Feb 7th 2018

\section{References}

[1] Kumar K, Ganguly K, Mazumdar K, Dutta N, Dastidar S, Chakrabarty A. Amlodipine: a cardiovascular drug with powerful antimicrobial property. Acta Microbiol Pol. 2003; 52(3): p. 285-92.

[2] Gupta P, Chanda R, Rai N, Kataria V, Kumar N. Antihypertensive, amlodipine besilate inhibits growth and biofilm of human fungal pathogen candida. Assay Drug Dev Technol. 2016 Jan; 14(5): p. online.

[3] Owen AJ, Reid CM. Cardio classics revisited focus on the role of amlodipine. Integr Blood Press Control. 2012 Jan; 2012(5): p. 1-7.

[4] Partha P, Nahid A. Oral therapy with amlodipine and lacidipine, 1,4-dihydropyridine derivatives showing activity against experimental Visceral leishmaniasis. Antimicrob Agents Chemother. 2008 Jan; 52(1): p. 374-7.
[5] Li Y, Pan C, Zhao Z, Zhao Z, Chen H, Lu W. Effects of a combination of amlodipine and imipenem on 42 clinical isolates of Acinetobacter baumannii obtained from a teaching hospital in Guangzhou, China. BMC Infect Dis. 2013 Nov; 13: p. 548.

[6] Hu C, Li Y, Zhao Z, Wei S, Zhao Z, Chen H, et al. in vitro synergistic effect of amlodipine and imipenem on the expression of the AdeABC efflux pump in multidrug-resistant Acinetobacter baumannii. PLoS One. 2018 June; 13(6): p. e0198061.

[7] Delaney J', Schneider-Lindner V, Brassard P, Suissa S. Mortality after infection with methicillin-resistant Staphylococcus aureus (MRSA) diagnosed in the community. BMC Medicine. 2008 Jan; 6: p. 2.

[8] Kavanagh KT, Abusalem S, Calderon E. the incidence of MRSA infections in the United States: is a more comprehensive tracking system needed? Antimicrob Resist Infect Control. 2017 April; 6: p. 34.

[9] Arêde P, Ministro J, Oliveira DC. Redefining the role of the $\beta$-lactamase locus in methicillin-resistant Staphylococcus aureus: $\beta$-lactamase regulators disrupt the MecI-mediated strong repression on mecA and optimize the phenotypic expression of resistance in strains with constitutive mecA. Antimicrob Agents Chemother. 2013 July; 57(7): p. 3037-45.

[10] Leticia I. L, Jed F. F, Shahriar M. Molecular basis and phenotype of methicillin resistance in Staphylococcus aureus and insights into new $\beta$-lactams that meet the challenge. Antimicrob Agents Chemother. 2009 Oct; 53(10): p. 4051-63.

[11] Fuda CCS, Fisher JF, Mobashery S. B-lactam resistance in Staphylococcus aureus: the adaptive resistance of a plastic genome. Cell Mol Life Sci. 2015 Nov; 62(22): p. 2617-33.

[12] O'Callaghan, Cynthia H. et al. Novel Method for Detection of B-Lactamases by Using a Chromogenic Cephalosporin Substrate. Antimicrob Agents Chemother. 1972 April; 1(4): p. 283-88.

[13] Chin N, Neu N, Neu H. Synergy of sulbactam and ampicillin against methicillin-resistant staphylococci. Drugs Exp Clin Res. 1986; 12(12): p. 939-42. 